\title{
Fluoride in groundwater: low-cost separation and stabilization by response surface optimization
}

\author{
S. Chakrabortty ${ }^{1} \cdot M$. Pal $^{1} \cdot M . \operatorname{Roy}^{2} \cdot$ P. Pal $^{1}$
}

Received: 11 March 2015/Revised: 20 September 2015/Accepted: 7 October 2015/Published online: 27 October 2015

(C) Islamic Azad University (IAU) 2015

\begin{abstract}
A nanomembrane-based hybrid treatment system for separation of fluoride from contaminated groundwater and its subsequent stabilization in a solid matrix through chemical coagulation-precipitation process using response surface optimization for safe disposal were designed and investigated. The continuous flat-sheet crossflow nanofiltration membrane module with well-screened commercial polyamide composite membrane succeeded in removing $99 \%$ fluoride from water while yielding a pure water flux as high as $158-160 \mathrm{~L} / \mathrm{m}^{2} \mathrm{~h}$ of a transmembrane hydraulic pressure of only 14 bars. Such an operating pressure is much lower than that required in reverse osmosis for the same separation. The designed system for the first time provides a total solution to a complex problem in a very simple, compact, flexible, and novel design that ensures continuous, steady, and hassle-free long-term operation without the necessity for frequent replacement of membranes. The approximate cost for production of $1000 \mathrm{~L}$ of safe drinking water from fluoride-contaminated groundwater computes to only $\$ 1.4$, indicating affordability in adopting the low-cost, high-flux water purification system by the affected people in many parts of the world.
\end{abstract}

Keywords Fluoride removal - Nanofiltration · Cross-flow system $\cdot$ Stabilization $\cdot$ Disposal

P. Pal

parimalpal2000@yahoo.com

1 Environment and Membrane Technology Laboratory, Department of Chemical Engineering, National Institute of Technology Durgapur, Durgapur 713209, India

2 Department of Management Studies, National Institute of Technology Durgapur, Durgapur 71320, India

\section{Introduction}

The problem of occurrence of fluoride in high concentration in groundwater is now one of the most serious toxicological and geo-environmental issues in several countries, like India (0.1-20 mg/L) (Patra et al. 2010; Jain 2012), Africa (1-60 mg/L) (Gizaw 1996), Sri Lanka (0.24-14.10 mg/L) (Jayawardana et al. 2012), and China $(0.2-8 \mathrm{mg} / \mathrm{L})(\mathrm{Gao}$ et al. 2013). Intake of fluoride in high concentration ( $>10 \mathrm{mg} / \mathrm{L})$ may cause "fluorosis," brittleness of bones, and even crippling of human bone structure, whereas a low dose can prevent "dental caries." In view of the adverse health impacts, the World Health Organization (WHO) has recommended $1.5 \mathrm{mg} / \mathrm{L}$ as the maximum permissible limit of fluoride (MCL) in drinking water (WHO 1993). This problem of effective treatment of contaminated groundwater to bring the concentration down to the WHO-prescribed level as well as ensuring safe disposal of fluoride rejects has thrown a challenge to the scientific community and policy makers. In many fluorideaffected areas, alternate sources of surface water are extremely limited and socioeconomic conditions of the affected people aggravate the problem. The four major conditions: adequate source, acceptable quality, transmission network, and affordable price to ensure access of the people of such areas to clean water are difficult to meet. This demands further research toward affordable technology for areas with limited alternate water resources.

Substantial research has been conducted on removal of fluoride from water, encompassing the broad technology areas of coagulation-precipitation, adsorption, ion exchange, and membrane separation. Aluminum sulfate is basically used as a coagulator in the coagulation process (He et al. 2015), whereas activated alumina (Tomar et al. 2014), resin (Boldaji et al. 2009), and different types of 
modified activated carbon (Angelina Thanga Ajisha and Rajagopal 2013) were used in the adsorption process. In case of membrane filtration, a different type nanofiltration membrane was used (Choi et al. 2001; Hu and Dickson 2006) for the significant removal of fluoride. Olgun and Atar (2011) reported effective adsorption of copper and cobalt which are frequently present in industrial wastewaters, by employing boron as an adsorbent. In the recent times, adsorption-based studies coupled with photocatalytic reactions involving nanoparticles like $\mathrm{TiO}_{2}($ Yola et al. 2014a) or a mixture of silver nanoparticles and colemanite ore waste (Yola et al. 2014b) for the respective removal of herbicides and dyes have caught the devotion of researchers. But a sustainable technology is yet to be evolved. For example, coagulation-precipitation process can produce large volumes of treated water, but the degree of purification may not be sufficient so as to reach the WHO-prescribed safe level. Disposal of huge volumes of sludge may be another problem. Adsorption-based processes are often not self-monitored with respect to quality of the water as even after the adsorbent material gets exhausted, people continue to collect water from the unit assuming it to be fluoride free. Disposal of large volume of fluoride-laden adsorbent also poses a problem. Energy-intensive regeneration of exhausted adsorbent material adds to the cost of the process and also goes against the environment. Membrane-based separations are carried out using different modules such as spiral-wound, hollow fiber, or plate and frame in dead-end mode, flat-sheet cross-flow types. In selecting such membrane modules, flux, rejection, and characteristics of the solution or mixture are determining factors. A flat-sheet cross-flow membrane module with polyamide composite nanofiltration membranes are found to effect good degree of separation of negatively charged species at high flux at relatively low transmembrane pressure (compared to the pressure used in reverse osmosis) on sustained basis (Islam and Patel 2007; Azami et al. 2011; Ponsot et al. 2013).

A continuous scheme of defluoridation from groundwater should provide its subsequent stabilization for safe disposal. Options for disposal of highly concentrated fluoride rejects are very limited. In many fluoride removal plants, fluoride rejects are generally dumped into the environment which leaves potential risk of recontamination of underground aquifers through natural percolation process. A possible solution to this disposal problem may be traced to stabilization of fluoride rejects from nanofiltration in some solid matrix (Yang and Dluhy 2002; Nath and Dutta 2012). Coagulation and co-precipitation with other minerals eventually binding fluoride in an insoluble form with such co-precipitators can lead to a viable solution. A few studies on such coagulation-precipitation involving salts of aluminum and calcium have been reported in the literature (Bowen and Welfoot 2002; Lisbona and Steel 2008; Kumar and Pal 2012). In such studies, pH, molar ratio, and mineral combinations have been found to influence stabilization process, but the stabilization parameters are not properly optimized thereby eliminating the mutual interaction effects. It is observed that very high doses of alum and lime have been used for the removal of very small amount of fluoride. Aluminum fluoride is not thermodynamically stable at the natural $\mathrm{pH}$ range (6-9) because of formation of aluminum hydroxide. Thus, the problem of instability remains, and it points to the necessity of optimization of the process parameters with higher accuracy. The present study is thus an attempt to fill this technology gap. This novel approach integrates a largely fouling-free and selective nanofiltration membrane module with a physicochemical coagulation-precipitation unit operating under response surface-optimized conditions for more effective stabilization of fluoride rejects paving the way for safe disposal. In the previous studies, only fluoride has been separated from groundwater by a special type nanofiltration membrane module where disposal of concentrated rejects has not been considered though it is very much harmful in nature. The present study comes up with the perception of the first time use of a continuous treatment scheme for the separation of fluoride from contaminated groundwater along with a sustainable solution that is stabilization of concentrated fluoride rejects. The present research work was carried out in National Institute of Technology Durgapur from March 2014 to December 2014.

\section{Materials and methods}

All chemicals used in the investigation were of reagent grade and were procured from Ranbaxy, India, Merck India, and Merck Germany. Fluoride standard was from Merck, Germany. Membranes (polyamide composite-based nanofiltration membrane) were purchased from Sepro Membranes, Inc. (USA). The geometry of the membrane is flat sheet, and the membrane surface area used in the investigation is $100 \mathrm{~cm}^{2}$. The $\mathrm{pH}$ tolerance range of the membrane is $2-11$, whereas the tolerance range of temperature and pressure are $273-323 \mathrm{~K}$ and $0-83 \mathrm{bar}$, respectively. The membrane gets rejected $99.5 \%$ sulfate ions and $90 \%$ chloride ions experimentally (provided by the manufacturer) at 10 bar of pressure.

All nanofiltration investigations were carried out in a laboratory-designed flat-sheet cross-flow membrane module capable of filtering over long duration without significant fouling over the membrane surface (Kumar et al. 2011; Pal et al. 2015) unlike the other widely used modules such as spiral-wound, hollow fiber, plate and frame, or 
tubular types (Pal et al. 2012). Spiral-wound configurations may have self-cleaning capability, but flat-sheet cross-flow membrane module is one such system that provides an immense sweeping action of fluid over the membrane surface, thus significantly reducing concentration polarization. Figure 1 presents the flow sheet of the treatment plant. In the previous research work (Chakrabortty et al. 2013), NF-1 was found to be the best membrane out of a given lot because it showed the highest removal efficiency of $98.5 \%$ at an operating pressure of 14 bar and cross-flow rate of $750 \mathrm{~L} / \mathrm{h}$, whereas the others two membranes (NF-2 and NF-20) offered 91 and $95 \%$ removal efficiency, respectively, under the same operating conditions. Contaminated water for the investigations was collected from some fluoride-affected areas of West Bengal, India, and such water was found to contain $17 \mathrm{mg} / \mathrm{L}$ of fluoride (Table 1). Operating pressure was varied in the range of 5-16 bar. Cross-flow rate across the membrane surface was maintained in the range of 200-800 L/h. Removal of fluoride from contaminated groundwater by the nanofiltration module was evaluated using the initial value $\left(C_{\mathrm{f}}\right)$ and the residual value $\left(C_{\mathrm{p}}\right)$ of fluoride concentration in feed stream and treated stream, respectively, and it has been expressed by the following equation:

$\%$ Removal efficiency $=\left(1-\frac{C_{\mathrm{p}}}{C_{\mathrm{f}}}\right)$

In the continuous run, fresh make-up water (contaminated) was continuously added to the feed tank at the same rate at which treated fluoride-free water was collected as filtrate. Two sections are present in the reported sustainable scheme: One is water treatment scheme and another is a stabilization scheme. "N-1" valve (nanofiltration valve) shown in the Fig. 1 was used to remove fluoride from groundwater while keeping "S-1" valve (stabilization valve) in closed condition. After 1 month of operation when stabilization is required, "S1 " valve is opened to transfer concentrated fluoride rejects to the stabilization unit keeping the "N-1" valve in closed position. Fluoride concentration in the rejects reaches a value of around $500 \mathrm{mg} / \mathrm{L}$ after operation of a $5000 \mathrm{~L}$ per day plant for a month where the feed water contains around $17 \mathrm{mg} / \mathrm{L}$ of fluoride. This means that after 1 month of operation, such a plant needs removal of the concentrated fluoride solution from the continuously operating loop by "S-1" valve, and the next downstream operation was thus stabilization of this concentrated fluoride in a solid matrix through a coagulation-precipitation process. The mean value of a triple set of data was used in the final computation in each case.

\section{Fluoride stabilization under response surface- optimized conditions}

Response surface methodology (RSM) is used to optimize a response of output variable which is influenced by several input variables, through an empirical model building by the assortment of some mathematical and statistical techniques.
Fig. 1 Membrane-integrated hybrid treatment scheme for separation and stabilization of fluoride

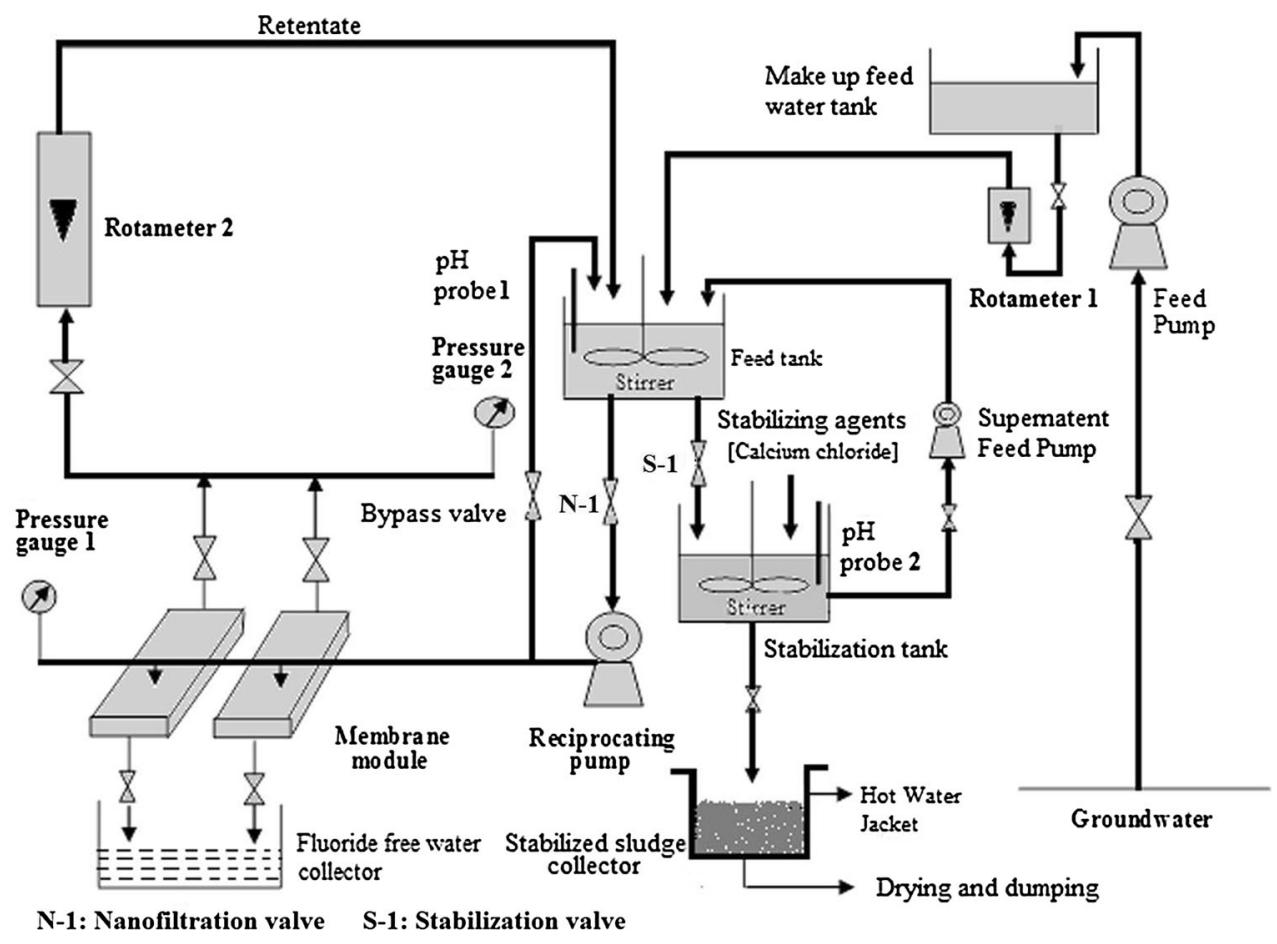


Table 1 Groundwater and concentrated water characteristics at different operation stage

\begin{tabular}{llccc}
\hline Water contaminants & Units & Feed side concentration & Permeate side concentration & Rejected after 1 month in the feed tank \\
\hline TSS & $\mathrm{mg} / \mathrm{L}$ & $166+0.81$ & $0+0$ & $4980+8.4$ \\
TDS & $\mathrm{mg} / \mathrm{L}$ & $320+0.74$ & $12+0.42$ & $9240+9.7$ \\
Conductivity & $\mu \mathrm{s} / \mathrm{cm}$ & $616+0.72$ & $32+0.82$ & $56+0.92$ \\
Salinity & $\mathrm{mg} / \mathrm{L}$ & $0.11+0.82$ & $0.04+0.66$ & $1.2+0.85$ \\
$\mathrm{pH}$ & - & $9.6+0.77$ & $7.2+0.72$ & $8.5+0.76$ \\
Fluoride & $\mathrm{mg} / \mathrm{L}$ & $17+0.72$ & $0.16+0.69$ & $510+4.4$ \\
Chloride & $\mathrm{mg} / \mathrm{L}$ & $85+0.86$ & $3.4+0.70$ & $2448+5.6$ \\
Sodium & $\mathrm{mg} / \mathrm{L}$ & $290+0.74$ & $12+0.68$ & $8340+9.1$ \\
Iron & $\mathrm{mg} / \mathrm{L}$ & $0.7+0.56$ & $0.03+0.88$ & $20.1+0.92$ \\
\hline
\end{tabular}

TSS total suspended solid, TDS total dissolved solid

The advantage of this method is to design optimization while reducing the overall cost and their associated numerical noise unlike the others expensive analysis methods such as finite element method or CFD analysis. But when the responses are independent, then effect of each parameter will affect output variables and the interactive effect of each parameter, which could be given different coefficient estimates which become complicated, and this is the drawback of this method. RSM can be used very effectively as a statistical tool for optimizing the process variables (Kumar and Pal 2012; Mourabet et al. 2012).

This design of experiment (DOE) software (version 8.0.6) was adopted for the first time in arriving at the optimum parameters of fluoride stabilization in a solid matrix through coagulation-precipitation. In this work, the central composite design (CCD) matrix of response surface methodology was applied to design the experiments to evaluate the interactive effects of four most important operating parameters, namely the initial concentration of fluoride, dose of calcium chloride, $\mathrm{pH}$, and stirring time which were considered as the independent variables, whereas fluoride stabilization efficiency was considered as the dependent variable. The CCD contained 16 star points, eight axial points, and six replicates at the center point, resulting in 30 experiments which covers the entire range of field of combinations of independent variables and results a second-order response surface. By following the CCD design, all the experiments were conducted in a randomized fashion. The required number of experiments $\left(N_{\mathrm{E}}\right)$ was also calculated by this manner:

$$
\begin{aligned}
N_{\mathrm{E}} & =\left(2^{p}+2 p+6\right)=\left(2^{4}+2.4+6\right)=(16+8+6) \\
& =30
\end{aligned}
$$

As presented in Table 2, the five codes used in the RSM were $-\mathrm{i},-1,0,+1,+\mathrm{i}$ indicating the five-level design as well as the minimum ( $(-)$ and maximum $(+)$ value of the variables, and the values should be within this range. The following empirical quadratic polynomial equation explains the predicting values of the dependent variable:

$$
\begin{aligned}
R \%= & \left(A_{0}+\sum_{i=1}^{n} A_{i} \cdot n_{i}+\sum_{i=1}^{n} A_{i i} \cdot n_{i i}^{2}+\sum_{i=1}^{n} \sum_{i=1}^{n} A_{i j} \cdot n_{i} \cdot n_{j}\right) \\
& \times 100
\end{aligned}
$$

$\mathrm{R}$ denotes the predicted response of fluoride stabilization, while $A_{0}, A_{i}, A_{i i}$, and $A_{i j}$ are offset terms for the model constants, linear coefficient, quadratic coefficients, and the cross-product coefficients, respectively. $n_{i}$ and $n_{j}$ are the codded values of the independent variables. The required number of
Table 2 Independent factors

\begin{tabular}{|c|c|c|c|c|c|c|c|}
\hline \multirow[t]{2}{*}{ Independent factors } & \multirow[t]{2}{*}{ Units } & \multirow[t]{2}{*}{ Symbol } & \multicolumn{5}{|c|}{ Codded levels } \\
\hline & & & $-\mathrm{i}$ & -1 & 0 & +1 & $+\mathrm{i}$ \\
\hline Initial fluoride concentration & $\mathrm{g} / \mathrm{L}$ & A & 0.25 & 0.5 & 0.75 & 1 & 1.25 \\
\hline Calcium chloride dose & $\mathrm{g} / \mathrm{L}$ & B & 2.5 & 5 & 7.5 & 10 & 12.5 \\
\hline $\mathrm{pH}$ & - & $\mathrm{C}$ & 4 & 5 & 6 & 7 & 8 \\
\hline Stirring time & Minute & $\mathrm{D}$ & 5 & 10 & 15 & 20 & 25 \\
\hline
\end{tabular}
range used in response surface methodology 
Table 3 Operating parameters and stabilization efficiency proposed by central composition design

\begin{tabular}{|c|c|c|c|c|c|c|c|}
\hline \multirow[t]{2}{*}{ SD } & \multirow[t]{2}{*}{ Run } & \multirow[t]{2}{*}{ F-conc. $(\mathrm{g} / \mathrm{L})$} & \multirow[t]{2}{*}{$\mathrm{CaCl}_{2}$ dose $(\mathrm{g} / \mathrm{L})$} & \multirow[t]{2}{*}{$\mathrm{pH}$} & \multirow[t]{2}{*}{ Stirring time (Min.) } & \multicolumn{2}{|c|}{ Stabilization efficiency $(\%)$} \\
\hline & & & & & & Observed & Predicted \\
\hline 19 & 1 & 0.75 & 2.50 & 6.00 & 15.00 & $90.0+0.45$ & 88 \\
\hline 18 & 2 & 1.25 & 7.50 & 6.00 & 15.00 & $91.2+0.22$ & 90 \\
\hline 3 & 3 & 0.50 & 10.00 & 5.00 & 10.00 & $83.0+0.35$ & 84 \\
\hline 10 & 4 & 1.00 & 5.00 & 5.00 & 20.00 & $90.5+0.12$ & 89 \\
\hline 16 & 5 & 1.00 & 10.00 & 7.00 & 20.00 & $91.7+0.42$ & 91 \\
\hline 23 & 6 & 0.75 & 7.50 & 6.00 & 5.00 & $66.2+0.34$ & 66 \\
\hline 8 & 7 & 1.00 & 10.00 & 7.00 & 10.00 & $91.6+0.25$ & 92 \\
\hline 25 & 8 & 0.75 & 7.50 & 6.00 & 15.00 & $66.8+0.48$ & 68 \\
\hline 20 & 9 & 0.75 & 12.50 & 6.00 & 15.00 & $67.0+0.28$ & 66 \\
\hline 2 & 10 & 1.00 & 5.00 & 5.00 & 10.00 & $92.0+0.28$ & 92 \\
\hline 9 & 11 & 0.50 & 5.00 & 5.00 & 20.00 & $40.3+0.15$ & 41 \\
\hline 28 & 12 & 0.75 & 7.50 & 6.00 & 15.00 & $66.5+0.13$ & 67 \\
\hline 21 & 13 & 0.75 & 7.50 & 4.00 & 15.00 & $66.9+0.12$ & 69 \\
\hline 22 & 14 & 0.75 & 7.50 & 8.00 & 15.00 & $67.1+0.22$ & 68 \\
\hline 12 & 15 & 1.00 & 10.00 & 5.00 & 20.00 & $90.5+0.31$ & 91 \\
\hline 4 & 16 & 1.00 & 10.00 & 5.00 & 10.00 & $90.8+0.24$ & 90 \\
\hline 24 & 17 & 0.75 & 7.50 & 6.00 & 25.00 & $66.2+0.05$ & 67 \\
\hline 5 & 18 & 0.50 & 5.00 & 7.00 & 10.00 & $42.0+0.11$ & 44 \\
\hline 13 & 19 & 0.50 & 5.00 & 7.00 & 20.00 & $41.0+0.18$ & 42 \\
\hline 26 & 20 & 0.75 & 7.50 & 6.00 & 15.00 & $63.6+0.21$ & 64 \\
\hline 11 & 21 & 0.50 & 10.00 & 5.00 & 20.00 & $40.0+0.39$ & 41 \\
\hline 27 & 22 & 0.75 & 7.50 & 6.00 & 15.00 & $64.9+0.15$ & 62 \\
\hline 29 & 23 & 0.75 & 7.50 & 6.00 & 15.00 & $67.0+0.28$ & 69 \\
\hline 15 & 24 & 0.50 & 10.00 & 7.00 & 20.00 & $41.8+0.14$ & 42 \\
\hline 1 & 25 & 0.50 & 5.00 & 5.00 & 10.00 & $41.9+0.35$ & 43 \\
\hline 14 & 26 & 1.00 & 5.00 & 7.00 & 20.00 & $90.5+0.29$ & 92 \\
\hline 17 & 27 & 0.25 & 7.50 & 6.00 & 15.00 & $20.0+0.28$ & 24 \\
\hline 6 & 28 & 1.00 & 5.00 & 7.00 & 10.00 & $93.0+0.24$ & 94 \\
\hline 7 & 29 & 0.50 & 10.00 & 7.00 & 10.00 & $40.4+0.37$ & 42 \\
\hline 30 & 30 & 0.75 & 7.50 & 6.00 & 15.00 & $64.0+0.33$ & 65 \\
\hline
\end{tabular}

experiments under operating conditions (Table 3) as suggested by Eq. 1 was conducted following central composite design. $\mathrm{pH}$ of the solution was adjusted using either concentrated orthophosphoric acid or $5 \mathrm{mM} \mathrm{NaOH}$ depending on the $\mathrm{pH}$ of the medium. After prolonged settling for $18 \mathrm{~h}$, the precipitate was collected by filtering the sample through filter paper (pore size of $0.45 \mu \mathrm{m}$ ), and the filtrate was subsequently analyzed for residual fluoride concentration.

\section{Temperature and reaction kinetics study of stabilized fluoride}

Temperature and reaction kinetics study of stabilization of fluoride in solid matrix was done under optimum conditions arrived through response surface methodology (RSM). Ten grams of calcium chloride was mixed with $1 \mathrm{~L}$ of fluoride solution that contained $1 \mathrm{~g}$ of fluoride concentration and was stirred for $10 \mathrm{~min}$ at a constant $\mathrm{pH}$ of 5 . While studying the effects of temperature on stabilization, stirred sample was kept in an incubator shaker, and the temperature was increased from 20 to $60{ }^{\circ} \mathrm{C}$ in stages of $5{ }^{\circ} \mathrm{C}$. During reaction kinetics study, samples $(10-\mathrm{ml}$ volume) were collected for $2 \mathrm{~h}$ with an interval of $10 \mathrm{~min}$ for the analysis.

\section{Toxicity characteristics leaching procedure (TCLP) test of solid fluoride matrix}

Solid fluoride matrix (basically calcium fluoride) that contained $320 \mathrm{mg} / \mathrm{g}$ of fluoride was subjected to toxic characteristics leaching procedure test. An extraction fluid was prepared during the TCLP test by mixing $5.7 \mathrm{ml}$ glacial acetic acid and $64.3 \mathrm{ml}$ of $1(\mathrm{~N})$ sodium hydroxide in 
$1 \mathrm{~L}$ deionized water where the $\mathrm{pH}$ was maintained at 5.0 (EPA 1992). The solid sludge was mixed with 20 times of extraction fluid and then agitated for $18 \mathrm{~h}$ at the room temperature $\left(30^{\circ} \mathrm{C}\right)$. After this agitation, supernatant fluid was taken and filtered through a filter paper of $0.45-\mu \mathrm{m}$ pore size. The whole leaching test was carried out at five different $\mathrm{pH}$ conditions.

\section{Analytics}

\section{Chemical analysis}

Measurement of $\mathrm{pH}$, fluoride, calcium, and sodium was made by Orion 4 star pH ISE benchtop ion meter of Thermo Electron Corporation, USA. Total dissolved solids, conductivity, and salinity were determined by InoLab Cond 720 and with electrode TetraCon 325 (WTW, Germany). Iron concentration was also measured by atomic absorption spectrophotometer (AAS100, PerkinElmer, and Germany) for cross-checking.

\section{Analysis of membrane morphology}

Membrane morphology was analyzed by scanning electron microscopy (SEM, Hitachi S-3000N, Japan) before and after each filtration operation (over long periods) to find out the changes in morphology and extent of membrane fouling. During SEM analysis, membrane pieces were freezefractured in liquid nitrogen and then gold-coated in ion sputter at $15 \mathrm{kV}$.

\section{FTIR study of $\mathrm{CaF}_{2}$}

Fourier transform infrared (FTIR) spectroscopy (Nexus 670, Thermo Electron Corporation, USA) was used to characterize bond nature of the fluoride with calcium. Calcium fluoride precipitates (before and after leaching) were dried in an oven at $45{ }^{\circ} \mathrm{C}$ for $48 \mathrm{~h}$, and then analyzed by FTIR spectroscopy. For the determination of bonding characteristics, $2 \mathrm{mg}$ of fine crushed sample was mixed well with $40 \mathrm{mg}$ of potassium bromide for preparing transparent pellets.

\section{Results and discussion}

\section{Effects of pressure and cross-flow rate on $\mathrm{F}, \mathrm{Cl}, \mathrm{Na}$, and $\mathrm{Fe}$ rejection and water flux}

Figure 2 illustrates the retention behavior of NF-1 membrane for different ions ( $\mathrm{F}, \mathrm{Cl}, \mathrm{Na}$, and $\mathrm{Fe}$ ) and water flux. A strong positive correlation of retention of solutes and

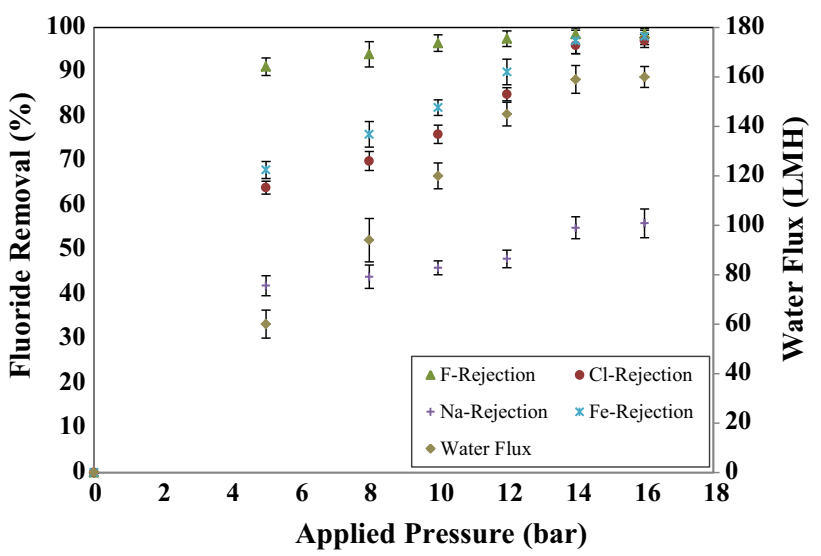

Fig. 2 Fluoride, chloride, sodium, iron removal, and pure water flux during nanofiltration under different operating pressures. Experimental conditions: NF-1 membrane, fluoride concentration of $17 \mathrm{mg} / \mathrm{L}$, $\mathrm{pH} 10$, pressure range $5-16$ bar, cross-flow rate $800 \mathrm{~L} / \mathrm{h}$, cross-flow velocity $1.25 \mathrm{~m} / \mathrm{s}$, temperature $35^{\circ} \mathrm{C}$

volumetric water flux with applied pressure is observed. The maximum removal efficiency of fluoride is observed to be around $99 \%$ at 14 bar pressure. At this transmembrane pressure, the module yields a pure water flux of $160 \mathrm{~L} /$ $\left(\mathrm{m}^{2} \mathrm{~h}\right)$. Solution-diffusion mechanism is one of the transport mechanisms of a nanofiltration membrane where solute flux and solvent flux are uncoupled, and due to this, with the increase in applied pressure, solvent flux increases without a corresponding increase in solute flux, resulting in a commensurate increase in solute rejection (Kumar et al. 2011). Moreover, due to the compressing effect of membrane, the steric resistance of the condensed membrane increases with increase in pressure, which enhanced the solute rejection (Murthy and Gupta 1997).

\section{Effects of cross-flow rate rejection and water flux}

The cross-flow rate was found to have significant influence on pure water flux as well as rejection of fluoride. At around 15 bar operating pressure, pure water flux was only $50 \mathrm{~L} /\left(\mathrm{m}^{2} \mathrm{~h}\right)$ and rejection of fluoride was only $85 \%$ at a cross-flow rate of $200 \mathrm{~L} / \mathrm{h}$. With increasing the cross-flow rate to $750 \mathrm{~L} / \mathrm{h}$ at the same operating pressure, the flux increased to $160 \mathrm{~L} / \mathrm{m}^{2} \mathrm{~h}$, while rejection of fluoride increased to $99 \%$. Such positive effects can be traced to significant reduction in concentration polarization by virtue of the sweeping action of the fluid on the surface of the membrane thereby preventing fouling. Reduction in concentration polarization in turn increases effective charged surface area of the membrane leading to increase in fluoride separation from water where Donnan exclusion principle dominates in transport mechanism. 


\section{Trend in membrane fouling with progress of time}

The permeate flux declines due to the buildup of concentration polarization layer on membrane surface. Reduced concentration polarization also enhances convective force which in turn improves solvent flux due to the very uncoupled nature of the solvent and solute fluxes during nanofiltration. The overall drop in flux over a long $144 \mathrm{~h}$ of operation is only $12-14 \%$ without rinsing of the membranes. With rinsing, this flux decline can be further arrested. SEM images (Fig. 3) of the NF-1 membranes before and after the filtration runs indicate further that fouling on the membrane surface of the present module is insignificant. The image does not show any significant morphological change on the membrane surface, even after prolonged filtration operation. This may be largely attributed to the speciality of flat-sheet cross-flow membrane module. Simple rinsing of the used membranes with 0.1 (N) $\mathrm{NaOH}$ and $10^{-2}$ molar $\mathrm{HNO}_{3}$ could largely remove the fouling and restore flux almost to its original level, indicating reversible nature of the fouling.

\section{Statistical results of the RSM for stabilization study}

Four parameters viz., initial fluoride concentration, calcium chloride dose, $\mathrm{pH}$, and stirring time were optimized by RSM using design expert software (version 8.0.6) for stabilization of fluoride. The list of experiments as suggested by RSM and the values of response (stabilization efficiency) for each sample obtained at corresponding experimental conditions are shown in Table 3. The quadratic model fits well to the experimental data as evident in the high value of the correlation coefficient, adjusted $R^{2}(0.97)$, predicted $R^{2}(0.96)$, high $F$ value (62), and low value of standard deviation (2.5), indicating further fitness of the model. The $R^{2}$ was found to be 0.98 implying that $98.2 \%$ of fluoride stabilization was accredited to the experimental variables studied. Effects of initial fluoride concentration, calcium chloride dose, $\mathrm{pH}$, and stirring time are significant as the $p$ values are less than 1 in each case. Adequate precision (AP) value was found to be 34 . Therefore, the quadratic model can be used for analyzing fluoride stabilization by the coagulation-precipitation process.

An empirical relationship between fluoride stabilization efficiency, and the four test variables were found by analysis of variance (ANOVA). The final regression function for response in terms of coded factors used in formulating the statistical model is given below

$$
\begin{aligned}
& \text { Stabilization efficency }(\%)=+74.67+(20.21 \times A) \\
& \quad-(1.88 \times B)-(1.21 \times C)-(2.46 \times D) \\
& +(0.44 \times A \times B)+(2.44 \times A \times C)+(2.69 \times A \times D) \\
& -(1.31 \times B \times C)-(0.31 \times B \times D)+(1.44 \times C \times D) \\
& -\left(3.76 \times A^{2}\right)+\left(2.61 \times B^{2}\right)+\left(0.86 \times C^{2}\right)+\left(0.24 \times D^{2}\right)
\end{aligned}
$$

A linear and close relationship between the predicted and the experimental values was observed. On average, against the model-predicted stabilization efficiency of $97.5 \%$, the experimental value was found to be around $97 \%$.

Stabilization of fluoride in the solid precipitate was found to be significantly influenced by fluoride concentration, calcium chloride dose, $\mathrm{pH}$, and stirring time of the medium as indicated in Fig. 4.

Figure 4a shows that stabilization efficiency increases from $44 \%$ at an initial concentration of fluoride of $0.5 \mathrm{~g} / \mathrm{L}$ to $94 \%$ at an initial fluoride concentration of $1.0 \mathrm{~g} / \mathrm{L}$ at the same calcium chloride dose of $10 \mathrm{~g} / \mathrm{L}$, stirring time of $15 \mathrm{~min}$ and $\mathrm{pH}$ of 6.0. This observation may be attributed to greater precipitation of fluoride (as calcium fluoride) at higher initial concentration of fluoride that helps attain supersaturation easily and quickly.

Figure $4 \mathrm{~b}$ shows the conjugate effects of stirring time and initial concentration of fluoride on fluoride stabilization. Surface plots in the figure show that the highest stabilization

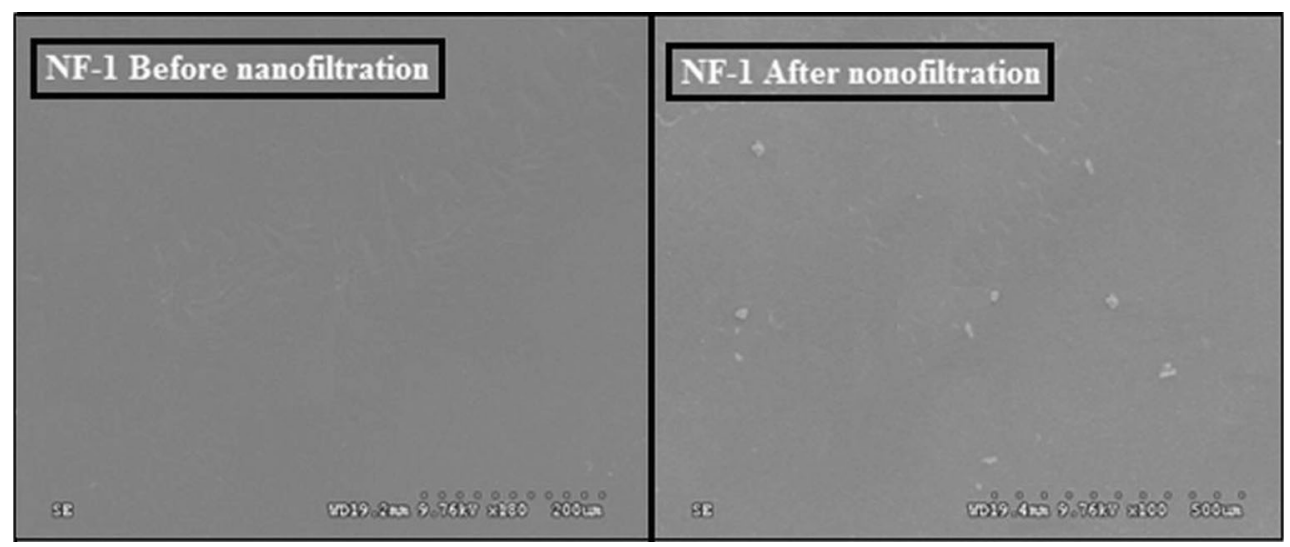

Fig. 3 SEM images of NF-1 membrane as obtained before and after the nanofiltration treatment of fluoride-contaminated groundwater 
(a)

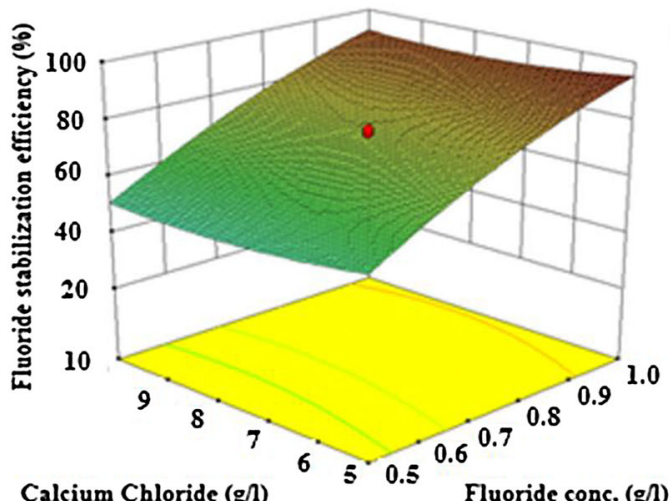

With Stirring time 15 minutes and $\mathrm{pH} 6$

(c)

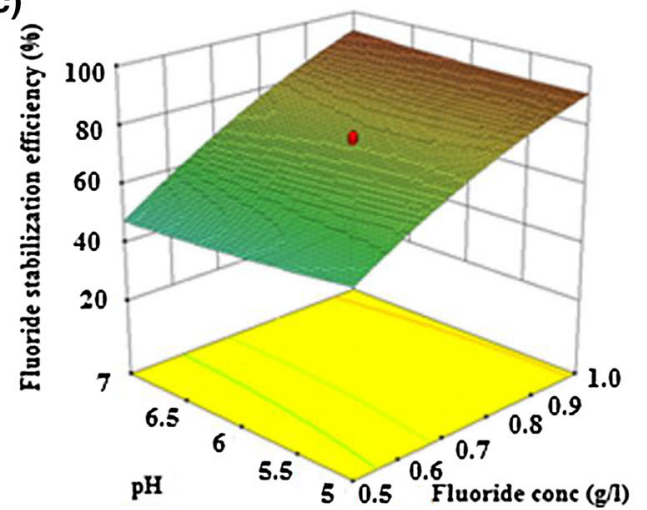

With Clacium Chloride $7.5 \mathrm{~g} /$ and Stirring time 15 minutes

Fig. 4 Response surface plot showing fluoride stabilization efficiency against operating parameters: a Effects of calcium chloride concentration and initial concentration of fluoride on fluoride stabilization efficiency at stirring time $15 \mathrm{~min}$ and $\mathrm{pH} 6$. b Effects of stirring time and initial concentration of fluoride on fluoride stabilization efficiency at calcium chloride concentration of $7.5 \mathrm{~g} / \mathrm{L}$

efficiency (97\%) is achieved over a stirring time of $20 \mathrm{~min}$ for initial fluoride concentration of $1 \mathrm{~g} / \mathrm{L}$ of fluoride and calcium chloride dose of $7.5 \mathrm{~g} / \mathrm{L}$ at a pH of 6.0.

Figure $4 \mathrm{c}$ indicates a positive correlation of initial fluoride concentration, $\mathrm{pH}$, and stirring time with stabilization efficiency. It shows that the fluoride stabilization efficiency increases from 48 to $94 \%$ with increase in $\mathrm{pH}$ from 5 to 7 as the initial concentration of fluoride increases from 0.5 to $1 \mathrm{~g} / \mathrm{L}$ keeping calcium chloride dose and stirring time fixed at $7.5 \mathrm{~g} / \mathrm{L}$ and $15 \mathrm{~min}$, respectively. With increase in $\mathrm{pH}$, sodium fluoride, and calcium chloride, salts get more dissociated into sodium, fluoride, calcium, and chloride ions, which plays a significant role in ionic coagulation.

Figure $4 \mathrm{~d}$ shows the effects of calcium chloride concentration and stirring time on the efficiency of fluoride stabilization at an optimum fluoride concentration of $0.75 \mathrm{~g} / \mathrm{L}$ and $\mathrm{pH}$ of 6 . The efficiency of fluoride stabilization (b)

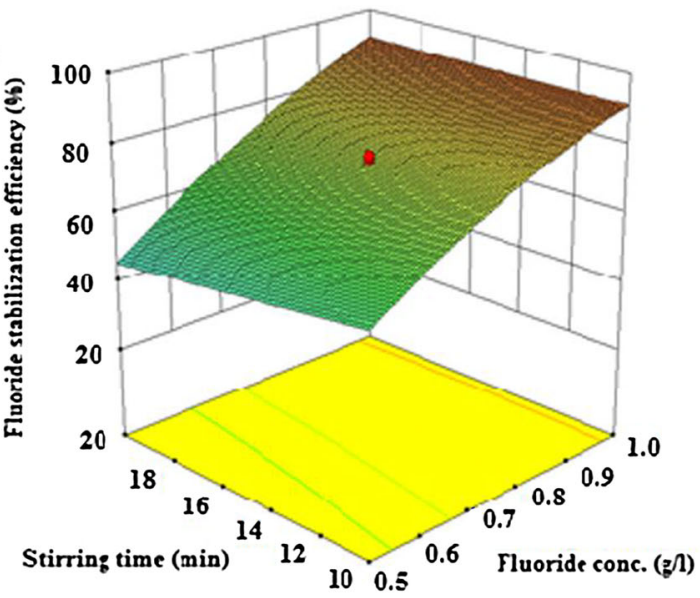

With Clacium Chloride 7.5 g/l and $\mathrm{pH} 6$

(d)

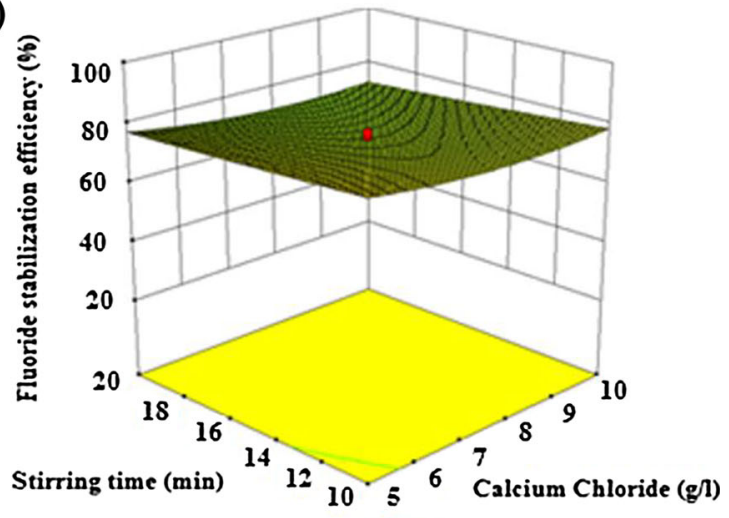

With Fluoride conc $0.75 \mathrm{~g} / 1$ and $\mathrm{pH} 6$

and $\mathrm{pH}$ 6. $\mathrm{c}$ Effects of $\mathrm{pH}$ and initial concentration of fluoride on fluoride stabilization efficiency at calcium chloride concentration of $7.5 \mathrm{~g} / \mathrm{L}$ and stirring time $15 \mathrm{~min}$. d Effects of stirring time calcium chloride concentration on fluoride stabilization efficiency at initial concentration of fluoride $0.75 \mathrm{~g} / \mathrm{L}$ and $\mathrm{pH} 6$

increases from 74 to $78 \%$ with increase in calcium chloride dose from 5 to $10 \mathrm{~g} / \mathrm{L}$ with deceasing stirring time. Response surface optimization during for fluoride stabilization yielded better stabilization conditions as the mutual interaction effects of the parameters could be avoided.

In each of the response surface plots of Fig. $4 \mathrm{a}-\mathrm{d}$, one red dot point is visible at the middle of figures which are nothing but a cluster of all the six center points (last numeric value according to Eq. 1). By replicating those center points, a very good power of prediction could be achieved at the region close to the middle of experimental zone.

\section{Effects of process temperature and reaction time on fluoride stabilization efficiency}

Figure 5a shows the effects of process temperature on fluoride stabilization efficiency. The efficiency increases 

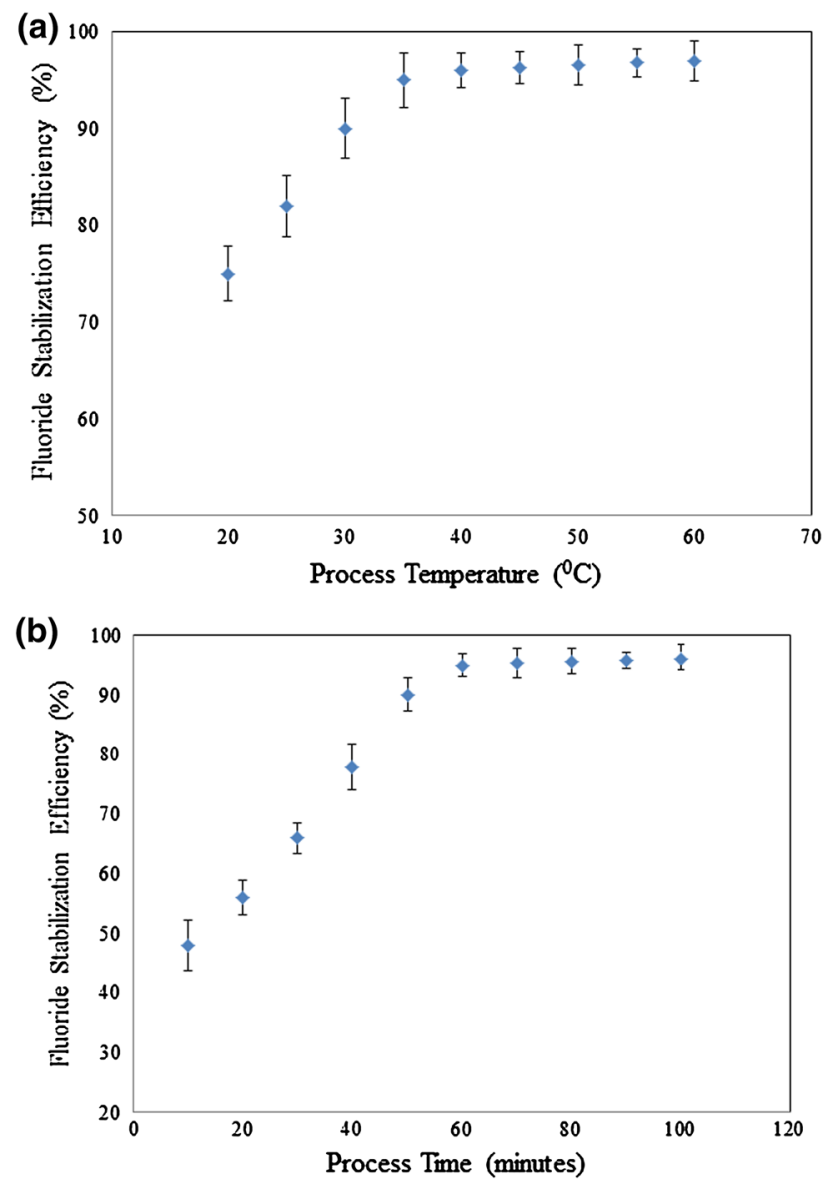

Fig. 5 Effects of process temperature and process reaction time on fluoride stabilization under response surface optimization. a Effects of process temperature on fluoride stabilization. b Effects of process reaction time on fluoride stabilization; optimum condition: $1 \mathrm{~g} / \mathrm{L}$ of initial fluoride concentration, $10 \mathrm{~g} / \mathrm{L}$ of calcium chloride concentration, Stirring time $10 \mathrm{~min}$ and $\mathrm{pH} 5$

from 75 to $97 \%$ with increase in temperature from 20 to $60{ }^{\circ} \mathrm{C}$. Figure shows that the stabilization efficiency increases sharply up to $35^{\circ} \mathrm{C}$, and then it increases slowly, which indicates that the process is endothermic in nature suggesting requirement of external heating.

The efficiency of stabilization increases from 48 to $96 \%$ with increase in time of reaction from 10 to $100 \mathrm{~min}$ (Fig. 5b). It is observed that the percentage stabilization efficiency increases continuously sharp up to $60 \min (94 \%)$ and then follows a minute increment $(96 \%)$ up to $100 \mathrm{~min}$. The active surface of calcium ions is more available for the reaction on to the target solute ( $\mathrm{F}$ ions) up to $60 \mathrm{~min}$. Afterward, until 100 min marginal efficiency in stabilization occurred due to non-availability of the active sites present on calcium chloride (Islam and Patel 2007). Henceforth, from the rigorous experimental investigations through response surface methodology, the optimum conditions (values of the process variables) for stabilization of fluoride were attained. The method shows that, for achieving around $98 \%$ of fluoride stabilization efficiency, $10 \mathrm{~g} / \mathrm{L}$ of calcium chloride should be added in the concentrated solution $(0.5 \mathrm{~g} / \mathrm{L}$ of fluoride concentration), maintaining the solution $\mathrm{pH}$ at 5.0 providing a stirring time of $10 \mathrm{~min}$. The process temperature and the reaction were maintained $308 \mathrm{~K}$ and $60 \mathrm{~min}$, respectively, during the investigation.

\section{TCLP and FTIR results of stabilized fluoride reject $\left(\mathrm{CaF}_{2}\right)$}

After TCLP test, $25 \mathrm{mg} / \mathrm{L}$ fluoride concentration was found in the supernatant which was leached out from the solid fluoride sludge that initially contained $320 \mathrm{mg} / \mathrm{g}$ fluoride, and this detected concentration of fluoride in supernatant is far below the maximum permissible leachable concentration level $(150 \mathrm{mg} / \mathrm{L})$ (Waste Classification Guidelines 2008), indicating adequate stabilization of fluoride in the solid matrix.

Figure $6 \mathrm{a}, \mathrm{b}$ illustrates the FTIR spectrum of the solid fluoride sludge $\left(\mathrm{CaF}_{2}\right)$ obtained during fluoride stabilization before and after TCLP test, respectively. The FTIR analysis (Fig. 6a) shows that the infrared spectrum of precipitates is close to that of the calcium fluoride as elucidated elsewhere (Azami et al. 2011). The reactive functional groups present in solid $\mathrm{CaF}_{2}$-based sludge, like $\mathrm{PO}_{4}{ }^{3-}, \mathrm{CO}_{3}{ }^{2-}, \mathrm{CH}$, and $\mathrm{OH}$ stretching band lie in the range of $550-3500 \mathrm{~cm}^{-1}$. The bands at 567 and $568 \mathrm{~cm}^{-1}$ indicate the presence of $04 \mathrm{PO}_{4}{ }^{3-}$ bond, while $1037-1095 \mathrm{~cm}^{-1}$ wavelengths suggest the presence of $\mathrm{v} 3$ $\mathrm{PO}_{4}{ }^{3-}$ bond (Azami et al. 2011). Peaks at 900, 1643, and $1658 \mathrm{~cm}^{-1}$ indicate the presence of $\mathrm{CO}_{3}{ }^{2-}$ bond. As it might have a chance to originate from the atmosphere and absorbed as a carbon di oxide form (Komath and Varma 2003). The water-stretching broadband was observed at $3000-3600 \mathrm{~cm}^{-1}$ wave number which indicated the presence of crystalline hydrate in solid precipitate. The carbonhydrogen bonding was attributed to $2854-2942 \mathrm{~cm}^{-1}$ band. Figure $6 \mathrm{~b}$ shows that no peaks are available at 1643 and $1658 \mathrm{~cm}^{-1}$ wavelength which is because the leaching process is performed in acid conditions at $\mathrm{pH}$ 5. Similarly an $\mathrm{O}-\mathrm{H}$ stretching band at 3400 wavelengths was also not found, which implies the sample was dried properly after leaching. Rest of the bands in Fig. $6 \mathrm{~b}$ are almost similar to those in Fig. 6a. The overall FTIR analysis shows that the solid fluoride sludge was nearly stable as there is no significant peak changes occurred before and after leaching test of fluoride-bearing solid matrix.

To ensure access of people in the affected regions to safe drinking water, the treatment technology should offer a sustainable solution. An adsorption-based system initially produces high volume of pure water at reasonable low cost, but with progress of time, adsorption bed gets saturated and the system no longer produces water with the same degree 


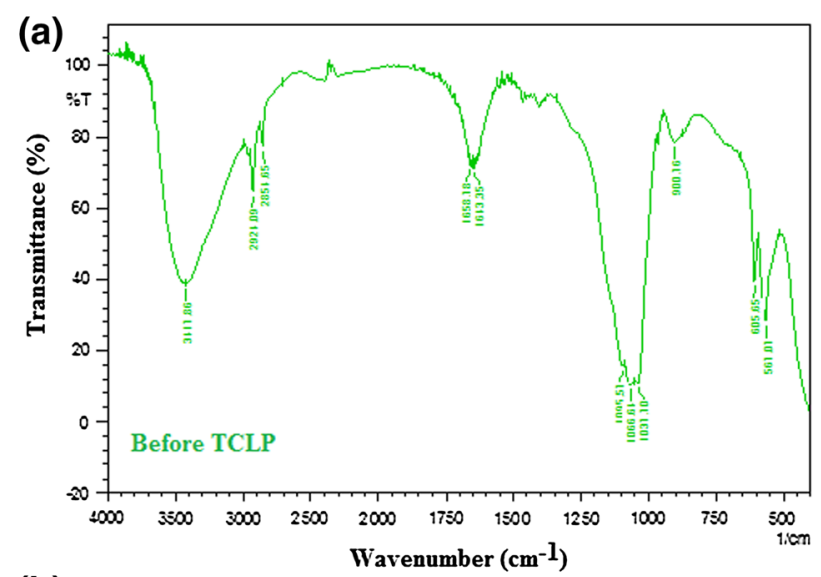

(b)

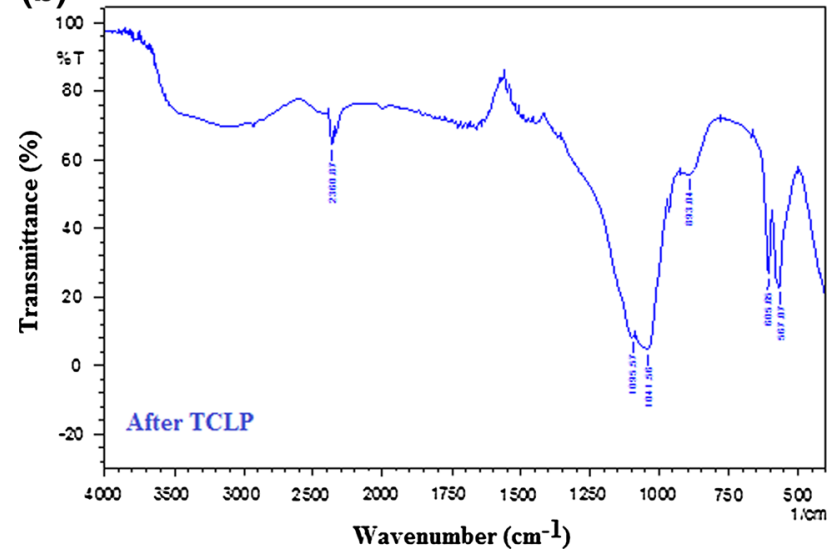

Fig. 6 FTIR results of solid calcium fluoride-based sludge at different conditions. a FTIR results before TCLP test. b FTIR results after TCLP test

of purification unless exhausted bed material is replaced. This means continuous monitoring and frequent replacement of adsorbent. A sustainable system in the present context is expected to ensure long-term trouble-free operation yielding the same high quality of water at reasonably low price. Such a system should be able to take care of the total environment without transferring a problem of pollution from one area to another area. The system should be considered in the context of the ground realities of the affected people where ease of maintenance, low price, and high quality of water are of paramount importance. The NF membranes not only remove fluoride but also ensure safe drinking water free from virus and bacteria. The separated fluoride is stabilized for safe disposal. The quality of water does not degrade with time in the present system though flux may decline to some extent but that may be restored by cleaning.

As the fluoride-bearing solid sludge passed the TCLP tests successfully, it can be classified as a non-hazardous waste, and it can be disposed safely through landfill (Ghurye et al. 2007). Such sludge if used in filling lowlying areas and in filling the rural road sides, this will not lead to any environmental problem. Fluoride-based sludge may be used in concrete as partial replacement of river sand, and it can improve the quality of the concrete (Rao et al. 2009). This stabilized sludge may also be used in manufacturing ceramic, glass-ceramic, and semiconductor material as well. Calcium fluoride sludge may be used as a component for making of ceramic product by mixing with sodium borate, sodium phosphate, and waste alumina using a low-temperature-sintering technology (Zhu et al. 2013). Ponsot et al. (2013) used calcium fluoride as a raw material to produce sintered glass-ceramic by direct sintering of "exhaust lime" mixed with clay. Liu and Li (2011) reutilized $\mathrm{CaF}_{2}$ sludge to the semiconductor industry as a "promoter." Addition of $\mathrm{CaF}_{2}$ sludge to fluxes can significantly reduce the melting point and hence improve the kinetics of the reactions. Azami et al. (2011) also showed that calcium fluoride can be used in dental applications. These only indicate potential of the use of fluoride rejects through effective solid matrix stabilization. Thus, the present system fulfills almost all the expectations of a sustainable system.

\section{Economic evaluation}

An economic evaluation was carried out for a plant capacity of $5000 \mathrm{~L} /$ day $\left(1825 \mathrm{~m}^{3} /\right.$ year $)$ intended to supply potable water to a community population of 500 . The system developed in the study yielded $160 \mathrm{~L} / \mathrm{m}^{2} \mathrm{~h}$ water fluxes while separating $99 \%$ fluoride from the groundwater at a transmembrane pressure of 14 bar. Considering running of the plant in two shifts $(2 \times 8 \mathrm{~h}=16 \mathrm{~h})$, the total volumetric flux requirement computes to $160 \times 16=2560 \mathrm{~L} / \mathrm{m}^{2}$ day, and numbers of module required computes to 8 (considering $0.25 \mathrm{~m}^{2}$ module area). For scale-up, cost assessment was done using sixth-tenth power law (Bruggen et al. 2001) defined as:

Scale - up cost $=$ Lab scale cost $\times\left(\frac{\text { Scale }- \text { up data }}{\text { Lab scale data }}\right)^{0.6}$

The cost computation details are presented in Table 4 . The cost assessment is based on the annualized investment cost and annualized operational cost. Annualized capital cost was computed by the following relationship:

Annualized capital cost $=\left(\frac{\text { Total capital }(\$) \times \text { Cost recovery factor }}{\text { Water flux per year }\left(\mathrm{m}^{3} / \text { year }\right)}\right)$

Cost recovery factor was dependent on plant project life ( $n=15$ years) and interest $(i=8 \%)$, and it can be calculated by the following equation: Cost recovery factor $=\left(\frac{i(1+i)^{n}}{(1+i)^{n-1}-1}\right) . \quad$ Again, $\quad$ annualized 
Table 4 Capital and operating cost of a 5000 L/day capacity water treatment plant

\begin{tabular}{lll}
\hline $\begin{array}{l}\text { Cost parameters } \\
\text { Capital cost }\end{array}$ & No of equipment with specification & $\begin{array}{l}\text { Cost value }(\$) \\
\text { Cost }(\$)\end{array}$ \\
\hline Cost for civil infrastructure & $10 \mathrm{~m}^{2}(5 \mathrm{~m} \times 2 \mathrm{~m})$ space & 400 \\
Membrane module cost & 8 no of module $\left(0.25 \mathrm{~m}^{2}\right.$ area) & 1200 \\
Large volume tank cost & 3 (Fiber tank, 5000 L capacity) & 600 \\
High-flow pump & 1 (Submersible pump) & 330 \\
High-pressure-pump cost & 1 (Diaphragm pump, Max. pr. 50 bar) & 1200 \\
Low-pressure-pump cost & 1 (Peristaltic pump) & 400 \\
Cost for main feed pipe & 6 m long and $0.15 \mathrm{~m}$ dia. & 300 \\
Others pipe fittings and & Rotameter $(2)$, Pr. Gauge $(2), \mathrm{pH}$ probe $(2)$ & 1500 \\
Electrotechnical cost & Stirring motor $(2)$ & 5930 \\
Total cost & & Cost $(\$ /$ year) \\
\hline Operating cost & Power consumption-1000 kWh $/ \mathrm{month}$ & 500 \\
\hline Electricity cost & Membrane needed-2.5 $\mathrm{m}^{2}, \mathrm{Cost}-50 \$ / \mathrm{m}^{2}$ & 252 \\
Membrane cost & Calcium chloride cost for stabilization & 500 \\
Chemical cost & No of labor 1 & 720 \\
Labor cost & & 1972 \\
Total cost & &
\end{tabular}

operational cost can be computed by the following equation:

Annualized operational cost $=\left(\frac{\text { Total operational cost }(\$ / \text { year })}{\text { Water flux per year }\left(\mathrm{m}^{3} / \text { year }\right)}\right)$

Thus annualized cost for production of $1000 \mathrm{~L}$ of drinking water from fluoride-contaminated water is the summation of annualized capital cost and annualized operating cost $(0.33+1.08)$ that stands at $\$ 1.41$

\section{Conclusion}

This study on separation of fluoride and its subsequent stabilization through response surface optimization culminates in a sustainable solution to the problem of groundwater contamination by fluoride. The system is capable of removal of fluoride from contaminated groundwater with high degree of efficiency in an environmentally benign and cost-effective way that takes total care of the disposal problem of a typical water treatment plant through stabilization of fluoride rejects. The stable solid matrix has several potential applications. The simple treatment scheme can be implemented at a reasonably low cost that is very likely to be affordable to the affected people as the computed cost of producing $1000 \mathrm{~L}$ pure water is only US $\$ 1.4$. The study is likely to raise scale-up confidence and pave the way for implementation of new plants using this technology.
Acknowledgments The authors are grateful to the Department of Science and Technology, Government of India, for the financial support through DST-INSPIRE fellowship program (DST/INSPIRE Fellowship/2012/271).

\section{References}

Angelina Thanga Ajisha M, Rajagopal K (2013) Fluoride removal study using pyrolyzed Delonix regia pod, an unconventional adsorbent. Int J Environ Sci Technol. doi:10.1007/s13762-0130485-8

Azami M, Jalilifiroozinezhad S, Mozafari M, Rabiee M (2011) Synthesis and solubility of calcium fluoride/hydroxy-fluorapatite nanocrystals for dental applications. Ceram Int 37:2007-2014

Boldaji MR, Mahvi AH, Dobaradaran S, Hosseini SS (2009) Evaluating the effectiveness of a hybrid sorbent resin in removing fluoride from water. Int $\mathrm{J}$ Environ Sci Technol 6(4):629-632

Bowen WR, Welfoot JS (2002) Modeling the performance of membrane nanofiltration-critical assessment and model development. Chem Eng Sci 57:1121-1137

Bruggen VD, Everaert D, Wilms D, Vandecasteele C (2001) Application of nanofiltration for removal of pesticides, nitrate and hardness from groundwater: rejection properties and economic evaluation. J Membr Sci 193(2):239-248

Chakrabortty S, Roy M, Pal P (2013) Removal of fluoride from contaminated groundwater by cross flow nanofiltration: transport modelling and economic evaluation. Desalination 313:115-124

Choi S, Yun A, Hong S, Ahn K (2001) The effect of co-existing ions and surface characteristics of nanomembrane on the removal of nitrate and fluoride. Desalination 133:53-64

Environmental Protection Agency US. 40 Code of Regulations (1992) (Part 261.31)

Gao XB, Zhang FC, Wang C, Wang YX (2013) Coexistence of high fluoride fresh and saline groundwaters in the Yuncheng Basin, northern China. Proced Earth Planet Sci 7:280-283 
Ghurye G, Younan JC, Chwirka J (2007) Arsenic removal from industrial wastewater discharges and residuals management issues. J EUEC 1:1-22

Gizaw B (1996) The origin of high bicarbonate and fluoride concentration in waters of the main Ethiopian Rift Valley, East African Rift system. J Afr Earth Sci 22:391-402

He Z, Liu R, Xu J, Liu H, Qua J (2015) Defluoridation by Al-based coagulation and adsorption: species transformation of aluminum and fluoride. Sep Purif Technol 148:68-75

Hu K, Dickson JM (2006) Nanofiltration membrane performance on fluoride removal from water. J Membr Sci 279:528-529

Islam M, Patel RK (2007) Evaluation of removal efficiency of fluoride from aqueous solution using quick lime. J Hazard Mater 143:303-310

Jain R (2012) Providing safe drinking water: a challenge for humanity. Clean Technol Environ Pol 14:1-4. doi:10.1007/ s10098-011-0446-1

Jayawardana DT, Pitawala HMTGA, Ishiga H (2012) Geochemical assessment of soils in districts of fluoride-rich and fluoride-poor groundwater, north-central Sri Lanka. J Geochem Explor 114:118-125

Komath M, Varma HK (2003) Development of a fully injectable calcium phosphate cement for orthopedic and dental applications. Bull Mater Sci 4:415-422

Kumar R, Pal P (2012) Response surface-optimized Fenton's pretreatment for chemical precipitation of struvite and recycling of water through downstream nanofiltration. Chem Eng J 210:33-44

Kumar R, Bhakta P, Chakraborty S, Pal P (2011) Separating cyanide from coke wastewater by cross flow nanofiltration. Sep Sci Technol 46:2119-2127

Lisbona DF, Steel MK (2008) Recovery of fluoride values from spent pot-lining: precipitation of an aluminum hydroxyl fluoride hydrate product. Sep Puri Technol 61:182-192

Liu WT, Li KC (2011) Application of reutilization technology to calcium fluoride sludge from semiconductor manufacturers. J Air Waste Manag Assoc 61(1):85-91

Mourabet M, ElRhilassi A, ElBoujaady H, Bennani-Ziatni M, ElHamri R, Taitai A (2012) Removal of fluoride from aqueous solution by adsorption on Apatitic tri calcium phosphate using Box-Behnken design and desirability function. App Surf Sci 258:4402-4410

Murthy ZVP, Gupta SK (1997) Estimation of mass-transfer coefficient using a combined nonlinear membrane transport and film theory. Desalination 109:39-49
Nath SK, Dutta RK (2012) Acid-enhanced limestone defluoridation in column reactor using oxalic acid. Proc Safe Environ Prot 90:65-75

Olgun A, Atar N (2011) Removal of copper and cobalt from aqueous solution onto waste containing boron impurity. Chem Eng J 167:140-147

Pal P, Chakrabortty S, Roy M (2012) Arsenic separation by a membrane-integrated hybrid treatment system: modelling, simulation and techno-economic evaluation. Sep Sci Technol 47:1091-1101

Pal M, Chakrabortty S, Pal P, Linnanen L (2015) Purifying fluoridecontaminated water by a novel forward osmosis design with enhanced flux under reduced concentration polarization. Environ Sci Pollut Res 22(15):11401-11411

Patra PK, Mandal B, Chakrabortty S (2010) The hydro geochemistry of fluoride rich groundwater in Birbhum District of West Bengal, India. Ecoscan 4(2\&3):209-211

Ponsot I, Falcone R, Bernardo E (2013) Stabilization of fluorinecontaining industrial waste by production of sintered glassceramics. Ceram Inter 39:6907-6915

Rao SM, Venkatarama Reddya BV, Lakshmikantha S, Ambikaa NS (2009) Re-use of fluoride contaminated bone char sludge in concrete. J Hazard Mater 166:751-756

Tomar G, Thareja A, Sarkar S (2014) Enhanced fluoride removal by hydroxyapatite-modified activated alumina. Int $\mathbf{J}$ Environ Sci Technol. doi:10.1007/s13762-014-0653-5

Waste Classification Guidelines (2008) Part 1: Classifying waste, Department of Environment and Climate Change NSW, Sydney (2008)

WHO (World Health Organization) (1993) Guidelines for drinking water quality, 1. World Health Organization, Geneva, pp 45-46

Yang CL, Dluhy R (2002) Electrochemical generation of alumina sorbent for fluoride adsorption. J Hazard Mater B 94:239

Yola ML, Eren T, Atar N, Wang S (2014a) Adsorptive and photocatalytic removal of reactive dyes by silver nanoparticlecolemanite ore waste. Chem Eng J 242:333-340

Yola ML, Eren T, Atar N (2014b) A novel efficient photocatalyst based on $\mathrm{TiO} 2$ nanoparticles involved boron enrichment waste for photocatalytic degradation of atrazine. Chem Eng J 250:288-294

Zhu P, Cao Z, Ye Y, Qian G, Lu B, Zhou M, Zhou J (2013) Reuse of hazardous calcium fluoride sludge from the integrated circuit industry. Waste Manag Res 31(11):1154-1159 